\title{
Stone Technology: An Old Tradition with a New Future
}

\author{
by Asher Shadmon
}

This article focuses attention on some fundamental facts about the use of rock as a building and ornamental material, especially dimension stone. The use of this traditional technology is now undergoing something of a renaissance, especially in developing countries where it can substitute for expensive imports of cement and other building materials. (Ed.)

Introduction

Specify a structural material as old as our planet that ean be used instantly and that was available when life started and shelter became a necessity and you have geomaterials, chiefly aggregate and dimension stone. Tissot's recent decision to launch "time in stone," its granite Rockwatch, is another landmark in the use of rock, but it is a paradox that an industry in existence as long as stone should only recently have begun to adapt itself to modern times. This is even more so in view of the fact that the cement and aggregates industries are producing a whole range of materials based on rock products to replace stone, and this by breaking up mountains of rock to put the stone together again!

Dimension stone is the term generally given to rock used in building construction (Fig. 1). From the crude block to the granite, marble or limestone tile, dimension stone acquires specific names, though to a geologist many of these terms are very loosely applied. For practical purposes, nine varieties cover the common stone types: marble, limestone, dolomite, granite, sandstone, basalt, quartzite, slate and

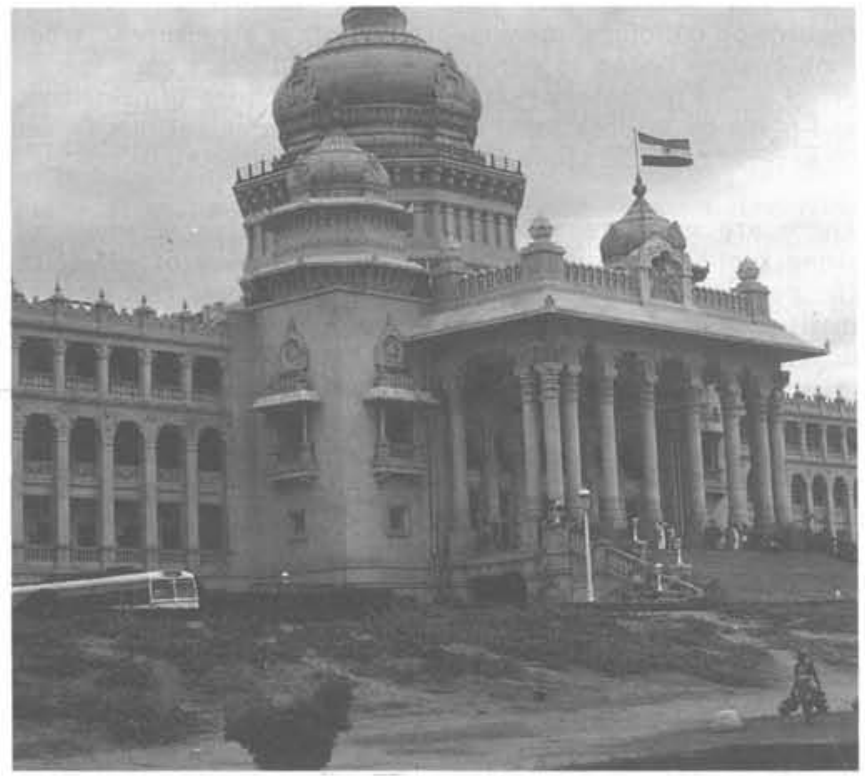

Figure 1: Stone on a grand scale. Government House, Bangalore, India.

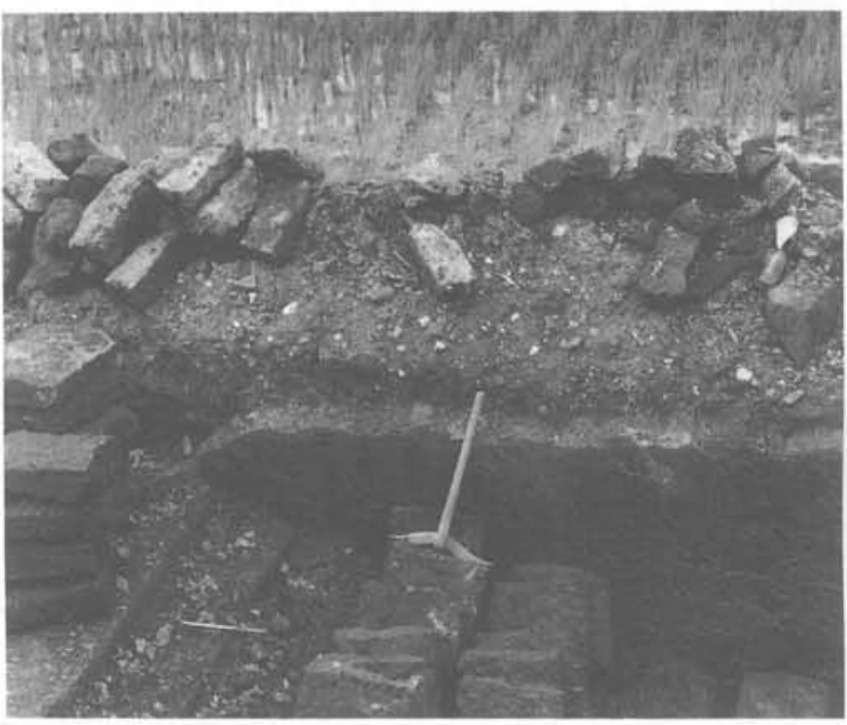

Figure 2: Piedra adobe (volcanic tuff) being extracted for use as construction material, Bulacan, Philippines. Note that excavated area in the background has been filled with soil and turned into rice paddy.

tuff (Fig. 2). For commercial purposes, "granite" refers to crystalline rocks with granitoid structures and textures, regardless of origin and grain size: it includes syenite, diorite, gabbro, gneiss and even schist. "Basalt" is used for fine-grained, black or dark coloured igneous rocks, including diabase and dolerite. Gneisses are often marketed as quartzites, and "marble" can refer to any calcareous rock that takes a polish, whether metamorphic or not.

The stone industry has further simplified the classification to a few varieties, which differ from country to country. In Scandinavia, for example, the industry differentiates hard stones from soft stones, the latter including limestones and marble, which may be harder when siliceous, if not more durable, than some igneous rocks like tuffs.

The extraction and dressing of stone is now a high technology that uses the most advanced and appropriate methods known. These involve, for example, the utilization in quarrying, processing and construction of high-performance stone working and cutting materials such as special steels, abrasives and industrial diamonds. However, there are also methods today that were also used by the ancients.

Stone materials have always been considered poor relatives of industrial minerals, and the even poorer ones of metals and oil. Furthermore, stone appears more often than not under the title "construction materials," which may be 
taught in civil and other engineering courses, in architecture and to art students, but seldom in the geosciences. Students who major in geology or mining engineering often learn less about geomaterials than those outside the geo-disciplines, and scientific data about stone are often dispensed by chemists and physicists. Indeed, to the stone technologist, decay is not less interesting than genesis.

Quarrying, until recently, has been scorned by mining engineers and regarded as something of an art based on empirical practices. Rising costs and steeply increasing demands have changed this picture, for more than 1,000 million tonnes of limestone are produced annually in the U.S.A. alone.

\section{A Measure of Progress}

The quantities and qualities of stone, sand and gravel used provide one way of measuring progress. High-value commodities, such as metals and fuels, extracted in bulk from poorer areas seldom contribute to the development of those regions. In contrast, stone materials are usually put to local or regional uses. The statement that in the U.S.A. the average person "consumes" 10 tonnes of geomaterials per year (including 4 tonnes of sand and gravel) says something about the standard of living in terms, for example, of transportation and communication facilities, housing, and the development of utilities.

Before 1900, building stone was a major urban construction material in many countries. Dimension stone was an early victim to the use of processed construction materials. With the advent of modern mass building, stone had to give way to brick and concrete, though villagers in the Third World continue today to use mudbricks, as well as straw, fibres, leaves and forest products.

Rapid population growth worked against expensive manual labour, and the use of stone declined in the first half of this century. Even cities such as Aberdeen, Jerusalem and Sydney with traditional or compulsory construction using natural stone (Diack, 1949; Kendall, 1948) had to turn to concrete materials. The use of stone has also suffered from whims of architectural fashion, with many ups and downs.

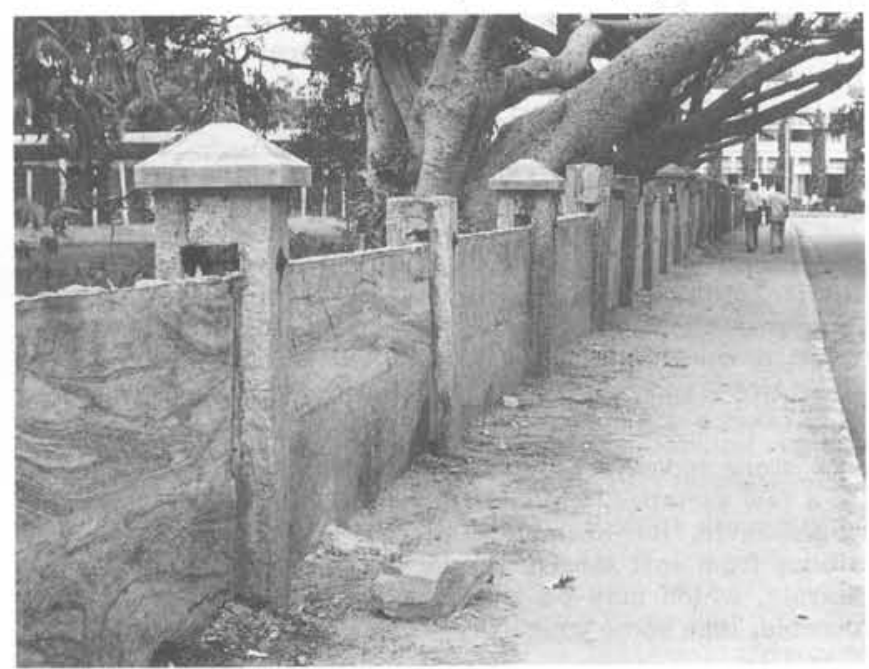

Figure 3: Fence constructed from hand-hewn slabs of gneiss, Bangalore, India.

In the last decade, there has been a tendency to use, especially in mountainous areas, undressed or rustic stones, which blend well with rocky hills. Dressed stone buildings continue to give more "solid" character to cities and urban areas. For example, dimension stone in France attained a production of a million tonnes by the turn of the last century, and although this dropped to 300,000 tonnes at World War II, it is now back to 3 million tonnes.
Many factors account for this come-back. The normalization of conditions after World War II, the inevitable reaction against plaster-cast facades with their high maintenance cost, and improvements in extraction and processing technology have all helped to increase the use of stone, especially in public and institutional buildings (Fig. 1).

\section{What is Stone Technology?}

There are six major areas of consideration in stone technology:

- Materials: properties of stone, qualities, terminology, weathering and durability.

- Sources: the location of stone, types of deposits, stone shapes, surface features and tectonic influences.

- Extraction: quarry planning development and practices, location, environmental aspects, removal from the deposit, extracting devices.

- Working: tools and techniques, splitting and breaking devices, industrial processes, finishing.

- Constructional uses: building stone types, dressing, masonry practices, foundations, field stone constructions.

- Development: costing, planning, investments, commercial aspects, pricing, conservation and preservation of resources.

There are, of course, many overlaps, and neither the economic nor the engineering geologist can claim exclusivity in an integrated approach. Like the traditional mining engineer who was a beast of many burdens, any geologist who specializes in stone must be a master of many disciplines. This is especially so in the domain of physical and petrological testing, where a geological background is required. A stone specialist requires thorough geological training and experience in petrology and petrography, a strong engineering slant, an interest in architecture and the plastic arts, an appreciation of historical applications, heritage and sources, including archeological and prehistorical, an interest in the economics of structural minerals, and a penchant for development and marketing.

While it may not be easy to locate a stone technologist, to find a single source for information on stone is exceedingly difficult. Ideally, there should be Stone Centres that have all the information required for stone development: inventories, literature, technological developments, experts available, testing and pilot plant facilities, historical records on buildings, monuments and other structures. When such centres began to germinate 15 to 20 years ago, the oil erisis led to budgetary restriction and a change in priorities, and plans by international development organizations to set up several regional stone centres did not materialize.

There are many reasons for the comparative slowness of stone technology to develop, including a lack of glamour, the generally small-scale nature of operations, the lack of institutionalization, and the common underrating of the capacities and potentials of stone. On the other hand, stone is one of the few local building materials that can be directly used with hand tools; further processing is optional. Stone needs no warehousing for storage, and packaging requirements are minimal. Shapes used are a matter of expediency and preference, and the various patterns require basically similar construction techniques.

In general, stone production for building requires low initial capital investment, labour-intensive inputs, low-grade skills and negligible energy inputs - all of which translate into low-production costs. However, the low value-to-weight ratio makes transportation and distribution a critical factor, putting a premium on proper planning of construction sites near stone sources. Small-scale artisan units and plants should thus be located near intended markets. 


\section{From Rock to Building Materials}

Typical dimension stone includes ashlar, which comprises pieces of square or rectangular cross-section, usually of constant size, and arranged in random fashion (uncoursed) or set out in regular rows (brought to courses). Also common is squared rubble (uncoursed, brought to courses, and snecked rubble which consists of small stone blocks used to fill interstices in rubble walls) and polygonal rubble, mainly from quarry waste. Quoins are blocks of stone set at an angle to walls, as in cornerstones. They are usually squared to provide a neat framework. Together with ashlar and rubble, slabby stones (flagstones) and trimming make up the four principal stone types for walls (Figs. 3,4). Natural slabby stone comes from thin layers and is used to face walls, fences and in the construction of pavements and floors. Trimming applies to cut stone not in the form of ashlar, and includes lintels, sills, caps and ornamental masonry components (A non, 1957; Shadmon, 1988).

No complicated processes are required to transform rock into building components - all that is required is to break and trim the stone. Appropriate technologies have been developed, which include the use of guillotines for trimming, and hammers, chisels, drills and bars to enable the worker to handle practically any situation. Simple tools like these are used in paving roads with stones in remote areas, building schools in rugged mountainous locations, and construction of houses in corrosive coastal and island environments.

Such tools depend on the fact that stone is brittle at low pressures. "Cutting" by breaking is initiated when fractures begin to spread under maximum compression. This is eaused by strains induced by the non-homogeneous nature of stone. A stress field of great concentration near the surface of stone will cause a spall or chipping, and spalling is the basis of stone dressing, for it requires comparative little energy. It causes instability and the released energy by loss of cohesion is used to enlarge the break. A first step towards this approach was the design of rock-splitters (guillotines), and in the last three decades specific splitting devices have appeared on the market, some including separate teeth that conform to irregular surfaces and transmit equalized breaking pressures.

Another improvement has been the induction of a stress field to control directions of splits and to obtain surfaces of a conchoidal nature with exaggerated convexity that give a sculptured effect. An experimental model of such a machine is at present in operation with good results. This uses the principle of the Brazilian Test to determine the tensile strength of brittle materials by creating a concentrated load that diminishes rapidly within the increased depth (Brace, 1964). Rock or stone splitting by power jacks or hydraulically operated wedges is not new but has received more attention recently. Attrition and abrasion involving sawing, grinding and polishing are also involved. Compared to spalling, abrasion uses much more energy, and machinery designed for shaping dimension stone should therefore be based on breaking rather than on abrasive action.

\section{Selecting Dimension Stone}

First, the bedding and layering should be checked to ascertain the thickness required for the application. Applying the hammer gives much information with respect to cohesion, hardness, soundness and, not less important, easy breakability. If a stone struck with a crowbar "rings true" and reverberates, then flaws are unlikely. A dull sound, as in striking a cracked clay vessel or flowerpot, indicates flaws.

Clayey, marly and the softer chalky rocks should be avoided. Soaking in water for a few days will give much information about hardness, coherence and porosity. Highly porous stone will increase considerably in weight; even hard marls and clays, may disintegrate during soaking. Important points for good workability are good cleavage and jointing.
A chisel-pointed hammer or mason's hammer, a chisel on smaller stones or a sledge hammer on larger ones and houlders, will give a good indication of breaking directions. Weathering changes can be observed by comparing the natural "skin" of the stone with a freshly broken surface. Without downgrading the value of systematically acquired knowledge of rocks, whether by practicing geology or stoneworking, intuitive judgements can be effectively given where no expert opinion is available.

Unconsolidated deposits may contain any of the main rock types mentioned earlier and are most convenient when occurring in fields, river beds, glacier accumulations, screes, terraces and beaches. The advantage here is that transport by rivers, waves and ice over long distances result in only the strong and stable stones being preserved. Included here are large residual core-stones that have resisted deep weathering of the rocks around them. Boulder quarrying is now widespread in Brazil (Fig. 5) and India, which are among the five top exporters of igneous rocks in the world (UNITAR, 1988).

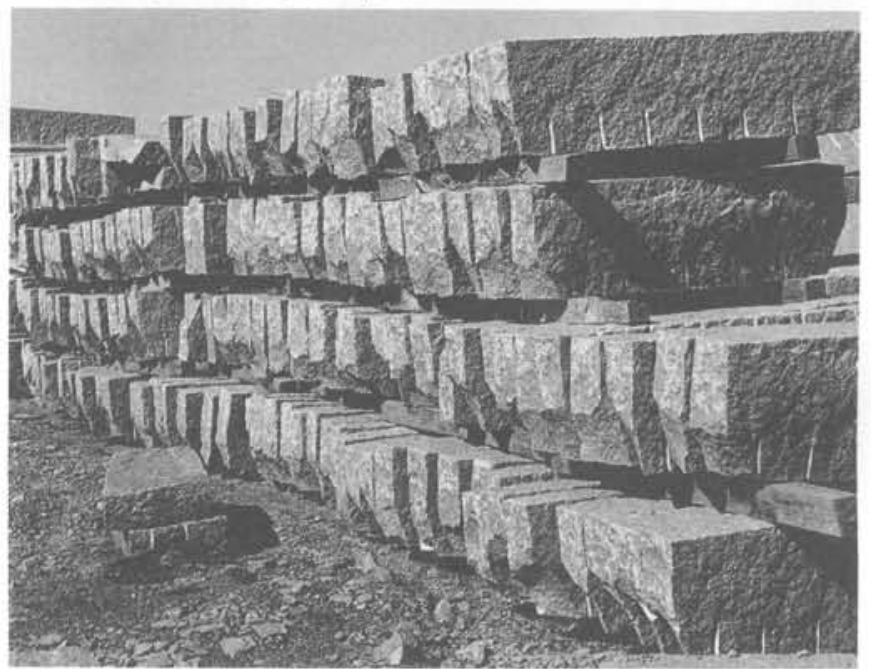

Figure 4: Granite curbstones $(15 \times 36 \times 120 \mathrm{~cm})$ awaiting use, Bohuslän, Sweden.

Sources for building stone are not always conventional. One of many examples where granite gneiss from mines has been used as material for low-cost housing is at Selebe-Pikwe, a nickel-copper mining town in Botswana (Massey, 1973). Blasting has fractured the rock along roughly parallel surfaces, and adequate supplies are available from waste heaps for use in "rondavels," the round houses indigenous to the area. Another recent innovation has been the use of a sulphur mix to cement stones together. The sulphur comes as a by-product of many mines and can be quite simply converted into a stabilized cement (Anon, 1977). In the case of Selebe-Pikwe, approximately 3,000 tonnes of sulphur were donated for a self-help housing project.

\section{Cutting and Extracting Technologies}

The removal of rock from quarry faces involves levers, bars or specially designed hand tools (for a general review see Shadmon, 1988). Hand drills, jack-hammers and mechanical jaws are used for eutting, channeling, wedging and other operations, depending on the nature of the deposit and the production and use requirements. The simplest way, though, is to pry a bed with a lever or, where fractures are wide enough, to force the rock apart with jacks.

Firesetting is a thermal method applied in small cottage industry installations where a fire is made on the surface of the rock and water poured over it when hot. The compressed air jack-hammer is still the most versatile piece of 

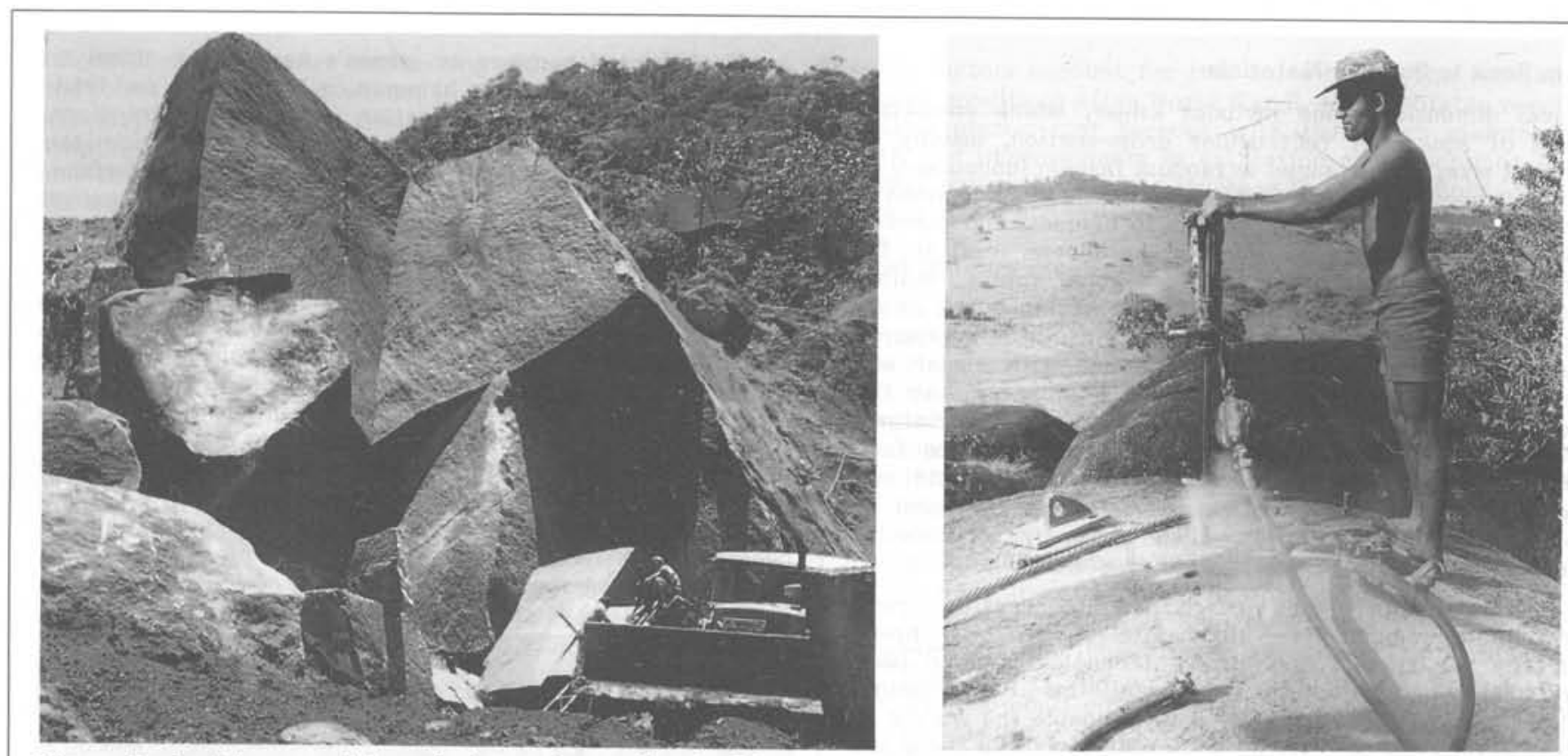

Figure 5: A-Primary cutting of a huge charnockite boulder at Ubatuba, Brazil. B-Drilling a granite boulder before breaking. Minas Gerais, Brazil

extraction equipment for small to medium size installations. At the other extreme are large pneumatic and hydraulic jumbos and other extraction equipment adapted especially for dimension stone production.

Where these methods are not feasible, wedges or plugs and feathers can be used, requiring drilling or cutting of shallow furrows or grooves for insertion of the wedges. The drilling can be done with pointed bars or plug-drill and hammers, jack-hammers or electric drills where a generator or a power grid is available. More recently, self-propelling mechanical chisels are used to split along bedding planes.

Sawing machines are available, ranging from a few HP engines to models with sawing dises 60 to $200 \mathrm{cms}$ in diameter that cut dimension stones right in the quarry (Fig. 6). Depending on the hardness of the stone, tungsten carbide or diamond edges are used. Traditional sawing with abrasivefed wires has now been superseded by the use of diamond beads mounted on a wire (Fig. 7), and considerable success has been obtained by using diamond wire to guarry blocks of igneous rocks, with euts of 5 to $16 \mathrm{~m}^{2} /$ hour obtained (UNITAR, 1988). The equipment can be operated from a remote control console.

Chain saws were at one time standard equipment for cutting coal in collieries. Since the 1960 s, they have been adapted for stone-cutting in quarries (Fig. 8) and are now widely used. This is especially so for the opening of underground faces, where they have replaced the more cumbersome cutting machines popular early this century.

Flame jet cutting has been used since the 1960 s in quarries, though restricted to polymineralic rocks. A concentrated high temperature flame $\left(2000^{\circ} \mathrm{C}\right)$ is confined to a narrow 10 $\mathrm{cm}$ strip of rock. The more varied the expansion coefficient of the different minerals, the more efficient the method, especially in quartz-bearing rocks. Flame cutting can also be economical for boring wide-diameter holes in sandstone, quartzitic rocks and dolomites, and for scabbling blocks prior to placement in frame saws. Mechanized flame jets have also been used recently in imparting thermal finishes to cut-stone slabs at the processing plant (Fig. 9).

The experimental cutting of stone by water jet has been reported since the early 1970s. It is now used to undercut 10-12 $\mathrm{m}$ of thick-bedded sandstone in the North Vosges district of France (Fig. 10). The water stream reaches a speed of $1,300 \mathrm{~km} / \mathrm{hr}$ under 650 bars pressure, cutting to a depth of $50 \mathrm{~mm}$ per return movement. An output has been achieved of $3 \mathrm{~m}^{2} /$ hour . With granites and quartz-bearing porphyries, a cutting rate of $2 \mathrm{~m}^{2}$ per hour has also been attained, though with higher speeds and pressures.

For harder stone, particularly igneous, wire-saw machines are often used, the advantages being superior cutting speeds and the elimination of staining on light-coloured materials by using iron-free abrasives, angle cuts being made around the axis of wire. The reluctance to use diamond blades in granite is due to the presence of hard and soft minerals, resulting in a jerky action on the cutting edge, thus reducing its life. However, the use of diamond blades in igneous rock with minerals of equal or similar hardness has been successful.

Several varieties of gang-saws with tungsten-carbide or diamond blades for primary sawing of stone are now in use, and the tendency is toward heavy construction to minimize vibration and thus save time in grinding by starting off with smoothly sawn surfaces. Recent developments include gang-saws without a central beam so that blocks of unrestricted length can be handled from the front to the rear of the machine.

Among primary sawing equipment, the vertical diamond band-saw (Fig. 11) is useful when cutting single slabs from a block for urgent orders or on very expensive material, as the

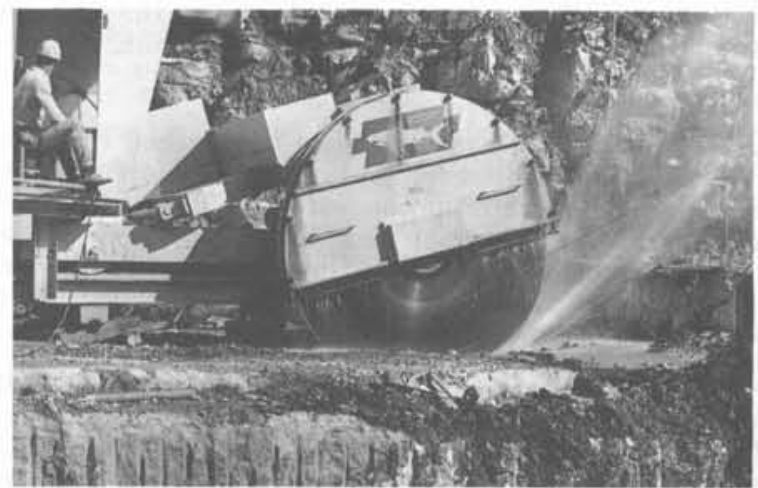

Figure 6: Cutting "marble" (Turonian limestone) by diamond disc in Galilee, Israel. 

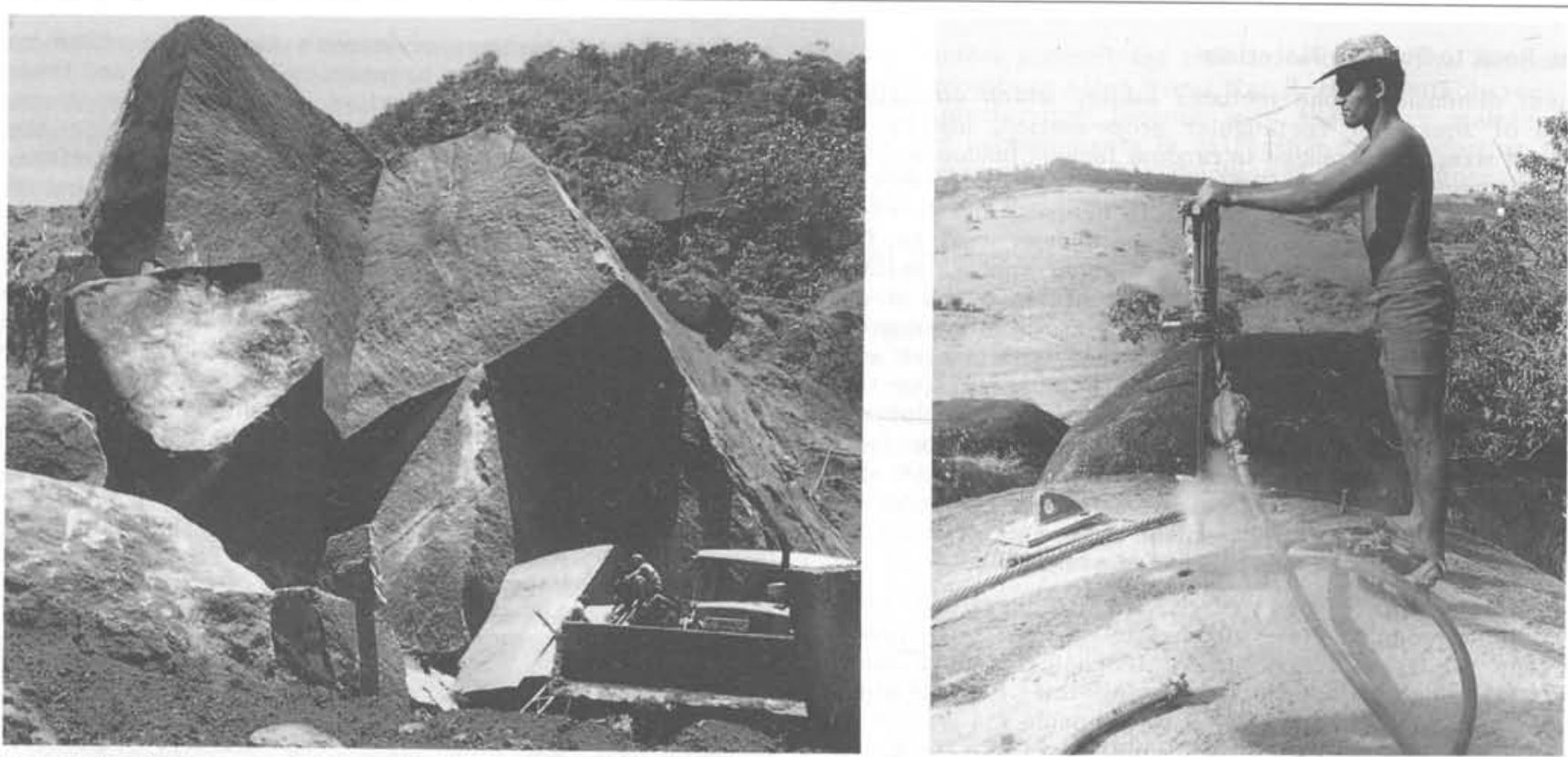

Figure 5: A-Primary cutting of a huge charnockite boulder at Ubatuba, Brazil. B-Drilling a granite boulder before breaking. Minas Gerais, Brazil.

extraction equipment for small to medium size installations. At the other extreme are large pneumatic and hydraulic jumbos and other extraction equipment adapted especially for dimension stone production.

Where these methods are not feasible, wedges or plugs and feathers can be used, requiring drilling or cutting of shallow furrows or grooves for insertion of the wedges. The drilling can be done with pointed bars or plug-drill and hammers, jack-hammers or electric drills where a generator or a power grid is available. More recently, self-propelling mechanical chisels are used to split along bedding planes.

Sawing machines are available, ranging from a few HP engines to models with sawing dises 60 to $200 \mathrm{cms}$ in diameter that cut dimension stones right in the quarry (Fig. 6). Depending on the hardness of the stone, tungsten carbide or diamond edges are used. Traditional sawing with abrasivefed wires has now been superseded by the use of diamond beads mounted on a wire (Fig. 7), and considerable success has been obtained by using diamond wire to guarry blocks of igneous rocks, with euts of 5 to $16 \mathrm{~m}^{2} /$ hour obtained (UNITAR, 1988). The equipment can be operated from a remote control console.

Chain saws were at one time standard equipment for eutting coal in collieries. Since the 1960 s, they have been adapted for stone-cutting in quarries (Fig. 8) and are now widely used. This is especially so for the opening of underground faces, where they have replaced the more cumbersome cutting machines popular early this century.

Flame jet cutting has been used since the $1960 \mathrm{~s}$ in quarries, though restricted to polymineralic rocks. A concentrated high temperature flame $\left(2000^{\circ} \mathrm{C}\right)$ is confined to a narrow 10 $\mathrm{cm}$ strip of rock. The more varied the expansion coefficient of the different minerals, the more efficient the method, especially in quartz-bearing rocks. Flame cutting can also be economical for boring wide-diameter holes in sandstone, quartzitic rocks and dolomites, and for scabbling blocks prior to placement in frame saws. Mechanized flame jets have also been used recently in imparting thermal finishes to cut-stone slabs at the processing plant (Fig. 9).

The experimental cutting of stone by water jet has been reported since the early 1970 s. It is now used to undercut $10-12 \mathrm{~m}$ of thick-bedded sandstone in the North Vosges district of France (Fig. 10). The water stream reaches a speed of $1,300 \mathrm{~km} / \mathrm{hr}$ under 650 bars pressure, cutting to a depth of $50 \mathrm{~mm}$ per return movement. An output has been achieved of $3 \mathrm{~m}^{2} /$ hour . With granites and quartz-bearing porphyries, a cutting rate of $2 \mathrm{~m}^{2}$ per hour has also been attained, though with higher speeds and pressures.

For harder stone, particularly igneous, wire-saw machines are often used, the advantages being superior cutting speeds and the elimination of staining on light-coloured materials by using iron-free abrasives, angle cuts being made around the axis of wire. The reluctance to use diamond blades in granite is due to the presence of hard and soft minerals, resulting in a jerky action on the cutting edge, thus reducing its life. However, the use of diamond blades in igneous rock with minerals of equal or similar hardness has been successful.

Several varieties of gang-saws with tungsten-carbide or diamond blades for primary sawing of stone are now in use, and the tendency is toward heavy construction to minimize vibration and thus save time in grinding by starting off with smoothly sawn surfaces. Recent developments include gang-saws without a central beam so that blocks of unrestricted length can be handled from the front to the rear of the machine.

Among primary sawing equipment, the vertical diamond band-saw (Fig. 11) is useful when eutting single slabs from a block for urgent orders or on very expensive material, as the

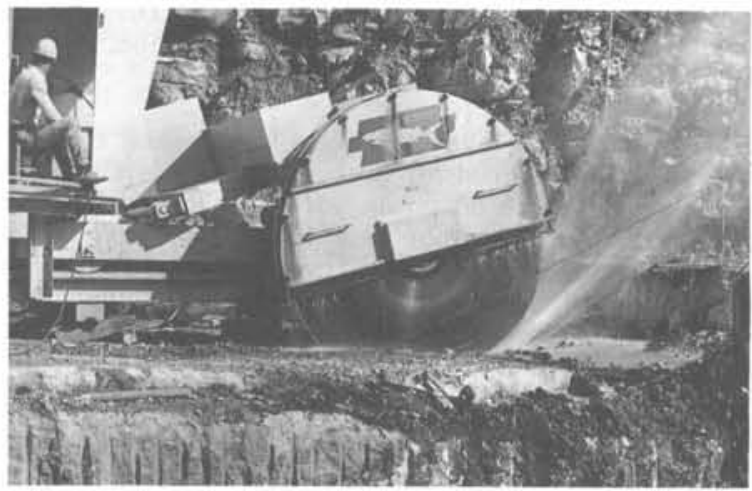

Figure 6: Cutting "marble" (Turonian limestone) by diamond disc in Galilee, Israel. 


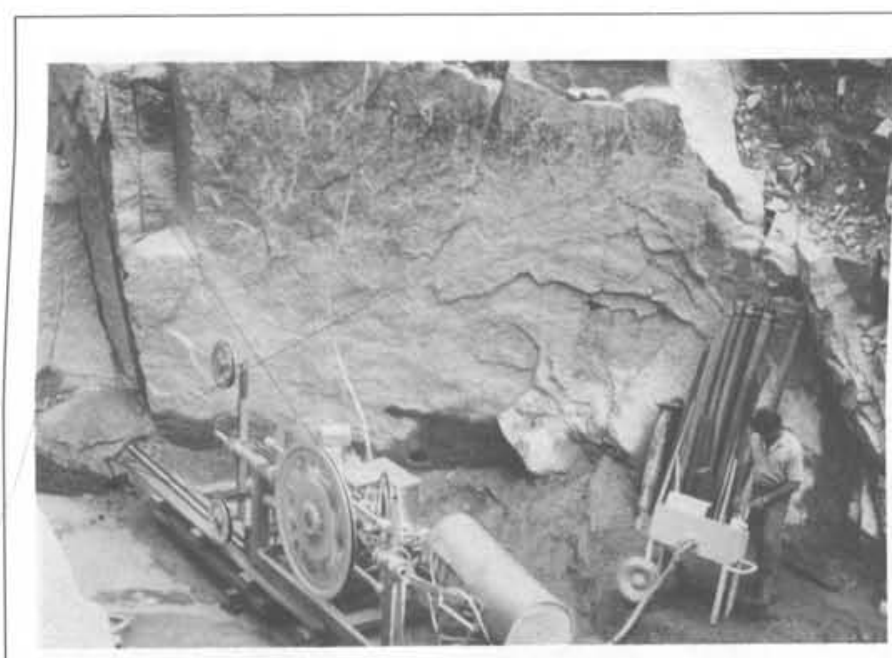

Figure 7: Cutting granite by diamond wire in Brazil. Photo courtesy of Diamond Boart, S.A., Brussels.

cut is only $1 / 8$ inch thick and saves material. A single diamond blade mounted in a special frame is now being tested industrially for cutting granite. Single blades (monolamas) fed by sand and other abrasives have been known and used for a long time, sometimes with the sole purpose of trimming blocks to prepare them for the gang-saw.

Stone breaking or working requires suitable support from benches, floors, sand-boxes, planks, pipes or angle iron. Whereas in extraction, the bar or lever is a most versatile tool used for prying, lifting, breaking, drilling and even testing, hammers take first place in stone-breaking. The ability to strike with a minimum of effort is important and depends on a combination of hammer weight and shape, handle length and the holding, swinging stance of the stoneworker. All these factors enable a worker with a hammer of, say, $5 \mathrm{~kg}$ to break a rock mass of many tonnes. Equally important are the natural breaking direction and the ability of the mason to direct blows (Fig. 12). This makes the difference between a fragmented result and fairly straight cuts with regular shapes.

After the hammer, the chisel is the most versatile tool for in shaping and dressing sione surfaces. A variety of chisels are available with tungsten carbide tips to save sharpening time, and compressed air models are also available. Dry cutting diamond dises are increasingly used for on-the-site

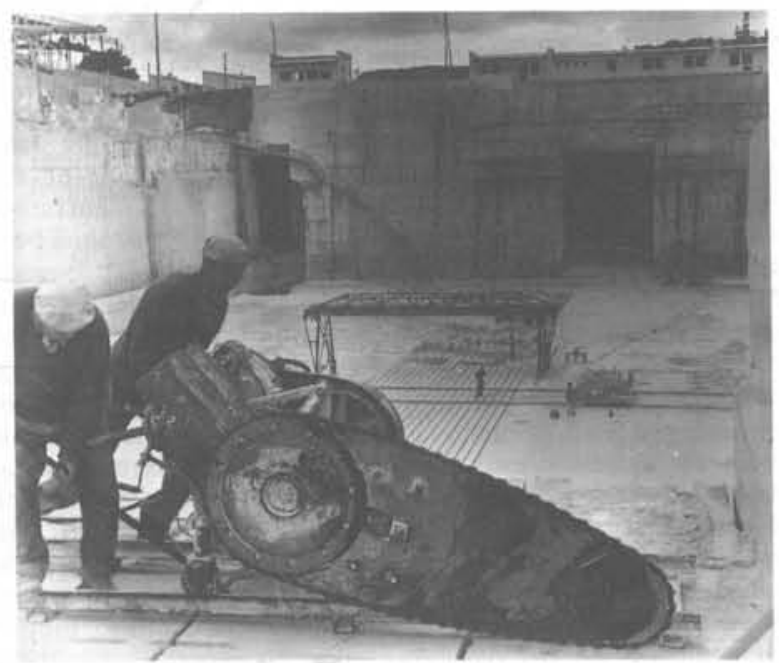

Figure 8: Cutting limestone in Fontvieille, southern France, by chain saw. trimming of building stones and are especially useful for cutting grooves for wedging. Their use is especially important for modular building stone units and components that require a tight fit or where channel or $V$-grooves and jointings are desired.

\section{Secondary Cutting}

Secondary sawing and cutting are terms used for trimming stone after primary cutting of blocks and larger units. Diamond saws are now in general use for this purpose and have largely replaced earborundum saws. The higher initial investment in diamond blades has proven to be worthwhile. Data vary on the correct cutting speeds, the ideal amounts and sizes of diamonds, and the proper matrix. They have to be carefully matched to the petrological properties of the stone. The emphasis is generally on automatic machines. For the machine that smoothes down the slab surface after sawing, the term "polishing machine" is used, although a large part of the output is roughing, gritting, grinding or honing and only the last stage is actual polishing.

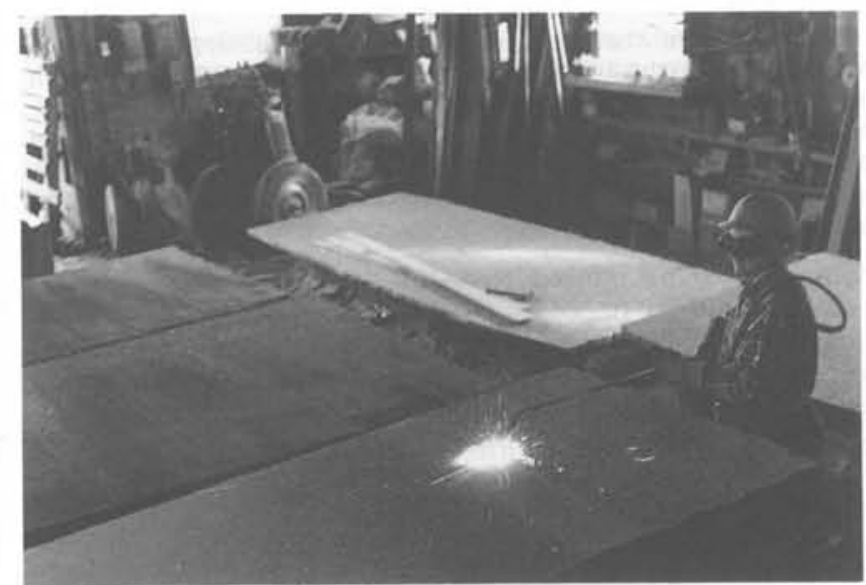

Figure 9: Using flame jet to put a surface finish on granite, Quebec, Canada.

The lubricant is of great importance. The cutting temperatures have to be just right, and then there is the wetting factor of the lubricant in relation to the cutting medium and the workpiece. The correct pressure must also be considered: a tendency to maximize the supply of water may cause a pressure pocket to be formed, thus reducing cutting efficiency.

\section{Polishing}

Polishing is used to bring out the full texture of the stone. The durability of a polished surface is commensurate with the care given during the processing. Surface treatment after polishing, e.g. by waxing, is often applied to improve the gloss, and to protect finished slabs during transport and handling. The desirability of a water-proof backing or protective surface treatment, for example silicone, is controversial (Price, 1981; Caroe and Caroe, 1984).

About a century ago, an arm-operated polishing machine was the first step in the mechanization of gritting operations after the slabs leave the saw. The "Jenny Lind" radial polisher, named after the famous Swedish singer because of the hum of the machine, is still in use today and is a prototype of the arm polisher. A rotary polishing dise mounted on a universal head can be swung by an operator over the stone table. A universal joint between the rubbing head and the spindle allows the head to take up any irregularities in the surface.

Automatic polishing machines work on the same principle of inter-changeable facings to a rotary polishing head, but are designed to track automatically over pre-set distances. 
They have a much higher output than a manually operated machine, produce an equally good finish and a large number of machine heads can be efficiently controlled by one operator. In polishing machines with sensors, the tool is lifted before it reaches an edge, and various thicknesses can be surfaced at the same time.

Different rock types require different polishing media. Great care must be taken to find the right compound, for much time can be saved in obtaining an optimum finish on the production line. The most commonly used agents are oxalic oxide, tin oxide and aluminum oxide. Oxalic acid is popular because it produces a high finish with little labour, but the polish is also less durable. Tin oxide or finely ground metallic lead mixed with putty powder (an undefined product) produces a high and durable gloss. Generally, hard polishing agents ean be recommended for soft rocks and soft agents for hard ones, because the relative hardness of the stone and the polishing agent is less important than the comparative melting temperatures.

\section{Mechanics of Polishing}

Little is known about the mechanics of polishing. This was originally thought to be a matter of fine grinding, in which ridges and depressions left by a coarse abrasive were reduced to sub-optical dimensions by the use of finely divided polishing agents. However, since materials used in polishing are very fine and often softer than the materials being polished, it is likely that they do not act as mere abrasives.

Beilby (1903) postulated that the friction during polishing causes an actual fusion of minute projections resulting in a flow, that is, an extremely thin liquid layer caused by local heating or chemical action with the production of an amorphous surface layer. This so-called Beilby layer recrystallizes immediately after formation on the cleavage planes, but remains amorphous elsewhere (Bowden and Hughes, 1937). Thus, the relative melting temperatures of polishing agents and the material to be polished are the key factors. Under certain conditions, calcite (melting point $\left.1,333^{\circ} \mathrm{C}\right)$ shows rapid polish and surface flow with a zine oxide polishing powder (melting point $1,800^{\circ} \mathrm{C}$ ), but little with cuprous oxide (melting point $1235^{\circ} \mathrm{C}$ ) under equal pressures.

The direction of polishing may also be important, as is the right pressure, especially in veined marbles where undue pressure tends to open softer veins. Factors such as the speed of the buff, degree of moisture and quantity of powder used may also affect the quality of polishing. Sand-blasting is applied in most countries as a surface treatment for granites and as an auxiliary method for lettering and ornamentation in marble. In Sweden, particularly, it is also applied as a main surface finishing for

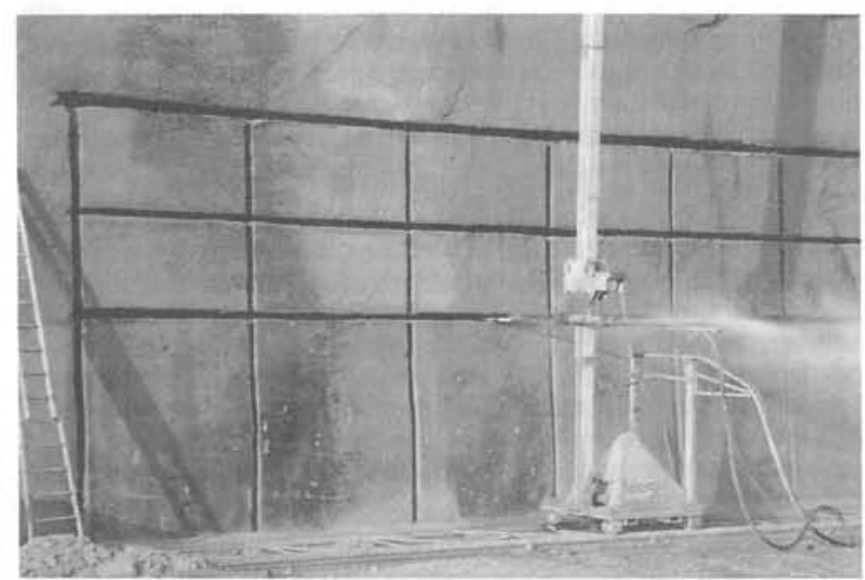

Figure 10: Cutting sandstone with water jet, Rothbach (Bas-Rhin), Vosges district of France.

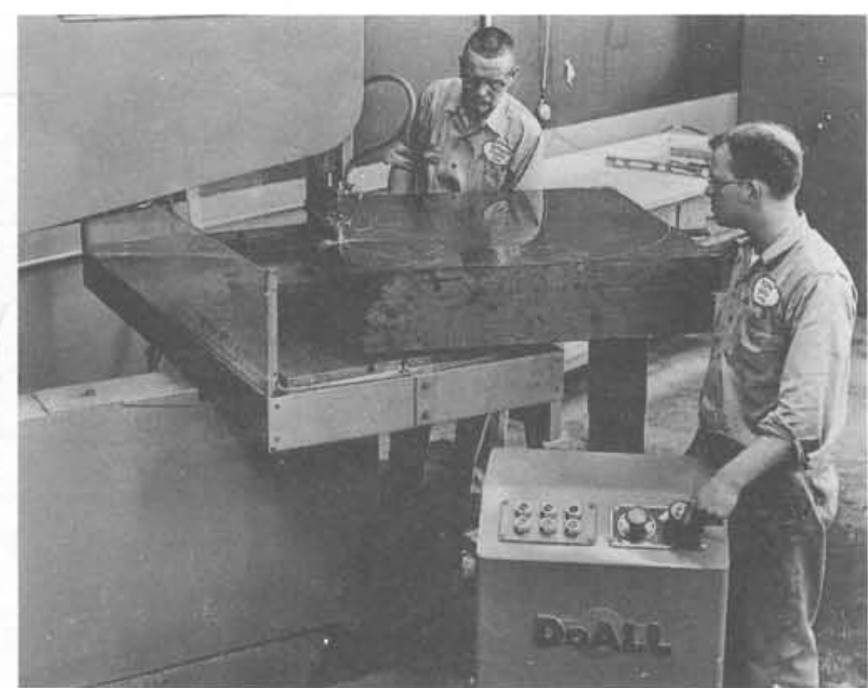

Figure 11: Cutting granite with a diamond-segmented band-saw, Elberton, Georgia, U.S.A.

marbles. In most cases, this finish is obtained by using abrasives other than the original sand that gave its name to the process, for example, emery, carborundum or garnet.

\section{Examples from the Caribbean}

Jamaica illustrates the stone potential typical in the Caribbean area. Sawkins in 1869 indicated more than 40 marble and stone locations. Marble varieties reported are metamorphosed limestones, dark Cretaceous and early Tertiary limestones, and the white limestone formations of Eocene, Oligocene and Miocene ages. The latter are off-white to shades of brown and pink.

However, despite earlier use of these rocks for construction of buildings, aqueducts and so forth, there are few dimension stone quarries where the development has been realistically conceived. This is one of the main factors why the industry never became successful, notwithstanding all the attention being paid to the development, legal and environmental aspects of a proper quarry industry.

Jamaica has the advantage of having a reservoir of welltrained geologists and institutional conditions, and attention to stone technology is presently increasing. An all stone house in Jamaica constructed with UN assistance is said to be $35 \%$ cheaper than previous houses of similar size constructed with high-energy building materials, not to mention its far greater resistance to storm damage!

The Public Building in St. Kitts is built from voleanic rocks, and the basalt tuffs of Grenada have been used for centuries, dressed and as rubble, in public buildings. Tuffs have found extensive use in St. Lucia, and in Antigua Eocene limestones were used in the cathedral and the court house of St. John's. The Sawstones of Barbados are of Pleistocene origin, and so are many varieties used in the Bahamas.

In Haiti and the Dominican Republic, an integrated stone development project has been producing interesting results, and these islands together with Cuba and Guatemala have already started to export marble. One project presently underway in the Caribbean is making exclusive use of local stone for self-help building, with $90 \%$ of the materials used located within a radius of $20 \mathrm{kms}$. Elsewhere integrated stone projects have fundamentally changed the face of entire areas, as fieldstones have replaced conventional materials at considerable savings, with aesthetic and environmental improvements. 


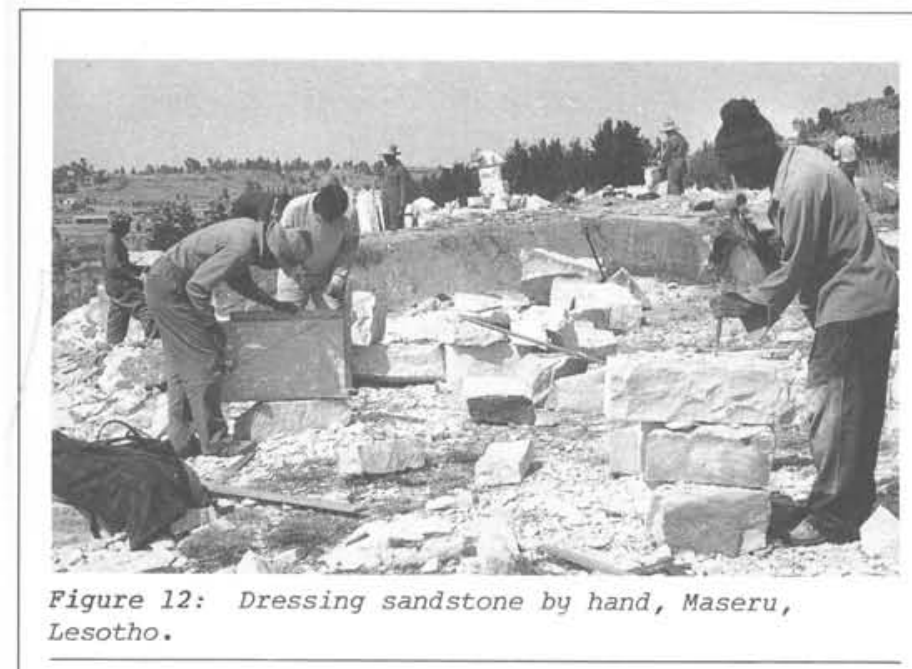

\section{Economic Factors}

That up to recently so old a material has adapted itself so little to modern times has been a function of slow technological growth, for even in more advanced countries, stone and marble are still applied by traditional methods. The recent trend is to revert to stone whenever economically possible. However, it is not yet generally understood that stone has been all along less expensive than alternatives. In some countries in Africa one side of the road is built with attractive rustic stonework whereas the houses opposite are built of concrete or cement blocks. The latter are, of course, regarded as having prestige, whereas the stone ones are "economic" housing!

The market ranges from the simplest and lowest cost construction to most prestigious edifices. Whereas a small house can be built with a cartload of stone, the 49-storey high-rise Arco Tower in Dallas, Texas, required $50,000 \mathrm{~m}^{2}$ for the exterior alone. The interior requirements for flooring, staircases and washrooms exceeded the cost of the material in the exterior cladding.

\section{International Trade}

There is considerable international trade in dimension stone. World-wide production of marble, for example, has increased twelve-fold, and granite production has increased 36 times in the last 35 years, reaching some 15 million tonnes in the mid-1980s. However, $95 \%$ of entire world production now comes from 27 countries, among which six in Europe together with the U.S.A. produce $70 \%$. Third World countries are now establishing themselves as suppliers in the international stone trade. India, Brazil and Taiwan have long been active and other nations in Asia, the Caribbean and Africa are now emerging as important suppliers of stone. These regions have considerable resources of marble and granite types, though much effort is still needed to attain a greater share for these countries.

The tendency of young countries to be critical of domestic products has been a handicap in the development of local stone industries, especially ornamental rocks. In 1970,51 of the 76 nations importing stone could be considered developing and could have used local resources or covered their needs from neighbouring countries, and the situation is much the same today. The lack of development of stone resources in these countries deprives the world building-stone market of quantities and varieties that could be used both at home and abroad, as well as the prospects of local industrialization (United Nations, 1976).

Stone prices do not fluctuate sharply, they only rise, unlike copper or mercury. There is little danger that substitutes for stone, unlike those for other primary materials, will seriously harm the market. However, the development of new resources especially in developing countries requires investment promotion backed by an effective inventory of stone available, and a pool of trained personnel.

\section{Training the Stone Mason}

In the past, long apprenticeships were considered as sufficient formal training, for there were no technological changes in the stone itself that required additional specialization. However, today the operator, whether using elaborate machines or simple mechanical devices, must meet specifications and tolerances with a high degree of precision, especially in industrialized processing. The variety of stone in use has also increased considerably, and delivery times have become more important than in the more leisurely past.

The irregularity in demand has left its mark on skilled craftsmen, many of whom have quit the industry, with no replacements forthcoming. There are few training facilities on professional and vocational levels for extraction and processing engineers. In some of the younger countries with an increasing demand for stone work, masons with experience in architectural details are altogether unavailable. Many a scheme where the architect was prepared to use stone did not materialize because of the lack of masons, and often skilled workers are imported for the duration of a project. A recent example is Belgium, a country with strong stone traditions, where Yugoslav specialists were brought in, together with the material, for the fixing of $4,000 \mathrm{~m}^{2}$ of marble in a new building in Brussels.

\section{Integrated Stone Development}

Extensive efforts in recent years to establish appropriate technologies in many parts of the world have led to the establishment of the Integrated Stone Development Planning (ISDP) concept. This applies both to developing nations and to developed countries, which have lagged behind in developing their stone resources when compared to mining. Because of the planning required, the ISDP concept should be considered early in any national master plan that covers, industrial or socio-economic aspects. Inclusion in planning ensures, for example, that economic stone prospects for certain areas are not lost by being built upon, or that expensive transport costs are saved where local resources can be used in place of cement blocks or concrete products manufactured elsewhere.

The pattern for ISDP begins with the making of an inventory of existing and potential stone resources. This is the base for planning, to ensure conservation and proper utilization of resources, and to prevent improper uses of land with regard to environmental and energy-saving factors. It also involves the introduction of appropriate technologies and improvement of current practices, the establishment of central testing and documentation facilities, and the training of national personnel.

ISDP promotes, inter alia, the introduction of stone products into rural and urban low-cost housing schemes, and road paving projects, the upgrading of stone for industrial and export purposes, the initiation of new products based on stone as a raw material (e.g. for use as fillers or for the manufacture of rockwool for insulation), and the intensified use of lime mortars. ISDP also encourages the establishment of small cottage-type and artisanal production units (e.g. for tourists), in addition to larger industries geared to export or to replace imports such as granite and marble for hotel construction.

Appraisal and exploration of bulk resources with little apparent glamour are not always obvious, yet they are of basic importance and out-of-proportion to the minor investments required when compared with other mineral ventures. Training efforts require high priority until such time as stone extraction and technology are recognized as acceptable disciplines. 
Dr. Asher Shadmon (P.O. Box 7344, Jerusalem 91072, Israel) has worked to develop stone industries in many countries, as a consultant to the UN and many other organizations. He is a past-president of the International Association of Engineering Geology and presently heads their Commission No. 10 on Building Stone and Ornamental Rock.

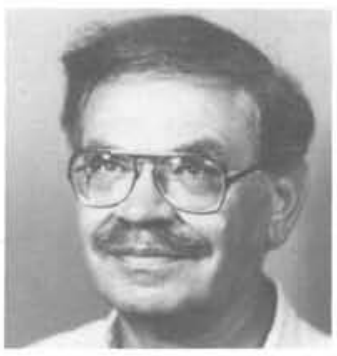

\section{References}

Anon, 1957. Glossary of terms for stone used in building. British Standard No. 2847. British Standards Institution, London, 38p.

Anon, 1977. Techniques for sulfur bonding for low cost housing. Southwest Research Institute, San Antonio, Texas, $53 \mathrm{p}$.

Beilby, G.T., 1903. Surface flow in crystalline solids under mechanical disturbance. Proceedings of the Royal Society (London), v. 72, p. 218-225.

Bowden, F.P. and Hughes, T.P., 1937. Physical Properties of Surfaces IV - Polishing, surface flow, and the formation of the Beilby Layer. Proceedings of the Royal Society (London), v. 160A, p. 575-587.
Brace, W.F., 1964. Brittle fracture of rocks. In: Judd W.R., (ed.), State of Stress in the Earth's Crust. Elsevier, New York, p. 111-180.

Caroe, A.D.R. and Caroe, M.B., 1984. Stonework: Maintenance and surface repair. Council for the Care of Churches, London, 56p.

Diack, W., 1949. Rise and progress of the granite industry in Aberdeen. Quarry Manager's Journal, London, 123p.

Kendall, H., 1948. Jerusalem. The City Plan; Preservation and development during the British Mandate, 1918-1948. His Majesty's Stationary Office, London, 122p.

Massey, N.W.D., 1973, Resources inventory of Botswana. Geological Survey Department, Mineral Resources Report, no. 3, Lobatse, Botswana, 39p.

Price, C.A., 1981. Brethane stone preservative. Building Research Establishment, Current Paper CP1/81. Her Majesty's Stationary Office, London, 9p.

Shadmon, A., 1988. Stone, an Introduction. Intermediate Technology Publications, 140p.

UNITAR, 1988. Stone in Brazil. United Nations Publication, Sales No. E.88, III.K.RR/35, 64p.

United Nations, 1976. The development potential of dimension stone. United Nations, Department of Economic and Social Affairs, New York, Sales No. 76/ESA/34, 95p.

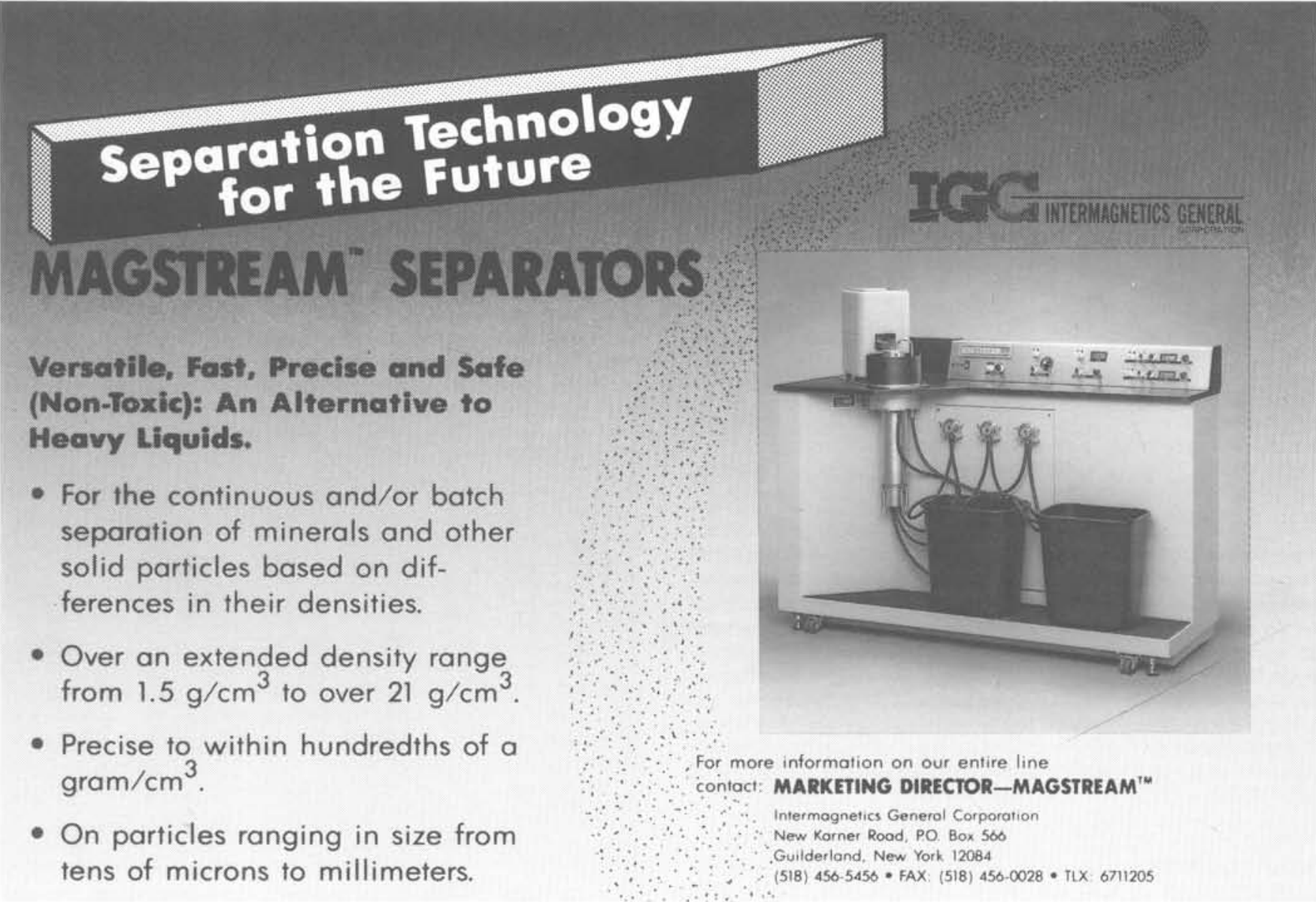

